\title{
GASIFIKASI LIMBAH TEMPURUNG KEMIRI SEBAGAI ENERGI ALTERNATIF MENGGUNAKAN UPDRAFT GASIFIER PADA LAJU ALIRAN UDARA BERBEDA
}

\section{GASIFICATION OF CANDLENUT SHELL USING UPDRAFT GASIFIER AT DIFFERENT AIR FLOWRATES}

\author{
Jemseng Carles Abineno ${ }^{\circledR}$, Johny Agustinus Koylal ${ }^{1}$ \\ ${ }^{1}$ Program Studi Manajemen Pertanian Lahan Kering, Politeknik Pertanian Negeri Kupang

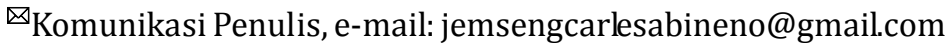 \\ DOI:http://dx.doi.org/10.23960/jtep-lv7i3.175-180
}

Naskah ini diterima pada 31 Oktober 2018; revisi pada 07 Desember 2018; disetujui untuk dipublikasikan pada 27 Desember 2018

\begin{abstract}
ABSTACT
Candlenut (Aleurites moluccana) is a plant with a productivity of 0.6 tons / ha. Processing of candlenut produces shell waste reaching $193.36 \mathrm{~kg} /$ ton. Analysis of the caloric value contained in the pecan shell reaches $0.021 \mathrm{MJ}$ / gr, so the energy contained in the pecan shell is $21 \mathrm{MJ} /$ ton with the total energy produced from the pecan shell reaching $4060.56 \mathrm{MJ} /$ year, but until now the hazelnut waste has not utilized. Agricultural waste, which is generally in the form of solids, can use energy in a simpler form through the gasification process. One way to convert candlenut waste is through the gasification process using an updraft gasifier. The treatment level (air flow rate) is tried to produce syngas, namely: $v 1$ (366.07 l / minute), v2 (462.09 l / minute), and v3 (545.11 l / minute). The results show that updraft gasifiers can produce gas (syngas), and are used as a source of heat energy for roasting and drying processes. The best gasification performance in the updraft gasifier occurs at the $v 2$ air flow rate (462.09 / / minute) which is the length of the syngas ignition reaches 48 minutes / $4 \mathrm{~kg}$ material or 16 minutes / $\mathrm{kg}$ material. Average ignition temperature of syngas $600^{\circ} \mathrm{C}$. The source of heat energy produced from candlenut shell biomass can be used for the process of drying and roasting agricultural produce.
\end{abstract}

Keywords: Gasification, shell, candlenut, gasifier, updraft

\begin{abstract}
ABSTRAK
Kemiri (Aleurites moluccana) merupakan tanaman dengan produktivitas 0,6 ton/ha. Pengolahan kemiri menghasilkan limbah berupa tempurung mencapai $193,36 \mathrm{~kg} / \mathrm{ton}$. Analisis nilai kalori yang terkandung dalam tempurung kemiri mencapai 0,021 MJ/gr, sehingga energi yang terkandung pada tempurung kemiri sebesar 21 $\mathrm{MJ} /$ ton dengan total energi yang dihasilkan dari tempurung kemiri mencapai 4060,56 MJ/tahun, namun sampai saat ini limbah tempurung kemiri belum dimanfaatkan. Limbah pertanian yang umumnya berupa padatan, dapat dimanfaatkan energinya dalam bentuk yang lebih sederhana melalui proses gasifikasi. Salah satu cara untuk konversi limbah tempurung kemiri adalah melalui proses gasifikasi menggunakan updraft gasifier. Level perlakuan (laju aliran udara) yang dicobakan untuk menghasilkan syngas yaitu:v1 (366.07 l/menit), v2 (462.09 l/menit), dan v3 (545.11 l/menit). Hasil penelitian menunjukkan updraft gasifier dapat menghasilkan gas (syngas), dan digunakan sebagai sumber energi panas untuk proses penyangraian dan pengeringan. Kinerja gasifikasi terbaik pada updraft gasifier terjadi pada laju aliran udara v2 (462.09l/menit) yaitu lama penyalaan syngas mencapai 48 menit $/ 4 \mathrm{~kg}_{\text {bahan }}$ atau $12 \mathrm{menit} / \mathrm{kg}_{\text {bahan }}$. Rata-rata suhu penyalaan berada pada kisaran $600^{\circ} \mathrm{C}$. Sumber energi panas yang dihasilkan dari biomassa tempurung kemiri dapat digunakan untuk proses pengeringan dan penyangraian bahan hasil pertanian.
\end{abstract}

Kata Kunci : Gasifikasi, tempurung, kemiri, gasifier, updraft 


\section{PENDAHULUAN}

Kemiri (Aleurites moluccana) merupakan tanaman dengan produktivitas sebesar 0,6 ton/ Ha. Hasil pengolahan kemiri dapat menghasilkan limbah berupa tempurung mencapai 193,36 kg/ ton. Pada umumnya masyarakat membuang kulit atau kemiri begitu saja, meski sebagian lagi digunakan untuk bahan bakar pengasap kemiri agar tetap kering. Namun pola pengasapan yang dilakukan oleh masyarakat dapat mengakibatkan pencemaran lingkungan. Di sisi lain, limbah atau tempurung kemiri ini sangat membahayakan pejalan kaki khususnya mereka yang tidak menggunakan alas kaki karena biasanya kulit atau tempurung kemiri yang sudah pecah keras dan tajam. Salah satu solusi untuk mengatasi permasalahan diatas adalah dengan memanfaatkan tempurung kemiri menjadi tempurung kemiri, melalui teknologi gasifikasi. Tempurung kemiri yang umumnya berupa padatan, dapat dimanfaatkan energinya melalui proses gasifikasi. Selain menghasilkan gas yang mudah dibakar, proses ini juga lebih ramah lingkungan jika dibandingkan dengan pembakaran langsung. Keuntungan lainnya adalah teknologi ini relatif sederhana sehingga dapat diaplikasikan langsung di masyarakat. Gas yang dihasilkan digunakan untuk keperluan rumah tangga dan, sebagai sumber energi panas dalam proses pengeringan, penyangraian bahan hasil pertanian.

Hasil analisis proximate dan ultimate (Abineno, 2012) menunjukkan bahwa tempurung kemiri memiliki nilai volatiles $51,6 \%$, carbon organic $32,2 \%$, abu $6,3 \%$ dan air 9,8\% dan nilai kalor $0.0206 \mathrm{MJ} / \mathrm{gr}$. Berdasarkan analisis proximate dan ultimate tersebut, maka energi yang terkandung dalam tempurung kemiri sangat besar, sehingga dapat dimanfaatkan untuk produksi gas melalui gasifikasi. Gasifikasi adalah proses konversi biomassa melalui oksigen terbatas (oksidasi parsial) menjadi bahan bakar gas biasanya dilakukan pada sebuah reaktor yang disebut gasifier. Gasifier merupakan reaktor kimia tempat proses kimia dan fisika yang kompleks terjadi seperti pengeringan, pemanasan, pirolisis, oksidasi, dan reduksi.

Gasifikasi dapat dibedakan berdasarkan mode fluidisasi, arah aliran dan gas agent yang diperlukan untuk proses gasifikasi. Berdasarkan mode fluidisasi, gasifikasi dapat dibedakan menjadi gasifikasi unggun tetap (fixed bed gasification), gasifikasi unggun bergerak (moving bed gasification), gasifikasi unggun terfluidisasi (fluidized bed gasification), dan entrained bed. Berdasarkan arah aliran, gasifikasi dibedakan menjadi gasifikasi aliran searah (downdraft gasification) dan gasifikasi aliran berlawanan (updraft gasification). Pada gasifikasi downdraft, arah aliran gas dan arah aliran padatan adalah sama-sama ke bawah (Pathak, dkk, 2008). Pada gasifikasi updraft gasifier, arah aliran padatan ke bawah sedangkan arah aliran gas ke atas. Pembakaran berlangsung dibagian bawah tumpukan bahan bakar dalam silinder, gas hasil pembakaran akan mengalir keatas melewati tumpukan bahan bakar sekaligus terjadi proses pengeringan. Bahan bakar dimasukkan kedalam ruang bakar melalui saluran pemasukan atas (Chopra dan Jain, 2007).

Abineno (2012) melakuka penelitian menggunakan updraft gasifier dengan variasi air flow rate menggunakan bahan bakar Tandan Kosong Kelapa Sawit (TKKS) menunjukkan bahwa semakin besar kapasitas udara bakar maka akan meningkatkan suhu pada zona gasifier, tetapi penggunaan kapasitas udara bakar yang tidak ideal, akan mengurangi nilai kalor gas produk gasifikasi (syngas). Penentuan besarnya laju aliran udara (air flow rate) untuk setiap biomasa sangat berbeda oleh karena itu pada penelitian ini dikaji laju aliran udara yang tepat untuk proses gasifikasi tempurung kemiri.

\section{BAHAN DAN METODE}

Penelitian ini menggunakan updraft gasifier sebagai reaktor untuk konversi biomasa menjadi gas mampu bakar (syngas) batch $4.2 \mathrm{~kg}$. Bahan bakar yang digunakan terdiri dari $4 \mathrm{~kg}$ tempurung kemiri dan arang pengumpang 0.2 $\mathrm{kg}$, sehingga total bahan bakar dan pengumpan sebesar $4.2 \mathrm{~kg}$. Updraft gasifier terdiri dari reaktor untuk proses untuk pengeringan, pirolisis, pembakaran, dan reduksi (gambar 1). Sebuah blower type sentrifugal dengan putaran 2800/menit digunakan sebagai penyuplai udara ke dalam reaktor. Pengaturan laju aliran udara dilakukan dengan membuka katub stop kran $90^{\circ}$, $180^{\circ}$ dan $270^{\circ}$. Pengukuran laju aliran udara dilakukan menggunakan Hot Wire Anemometer 


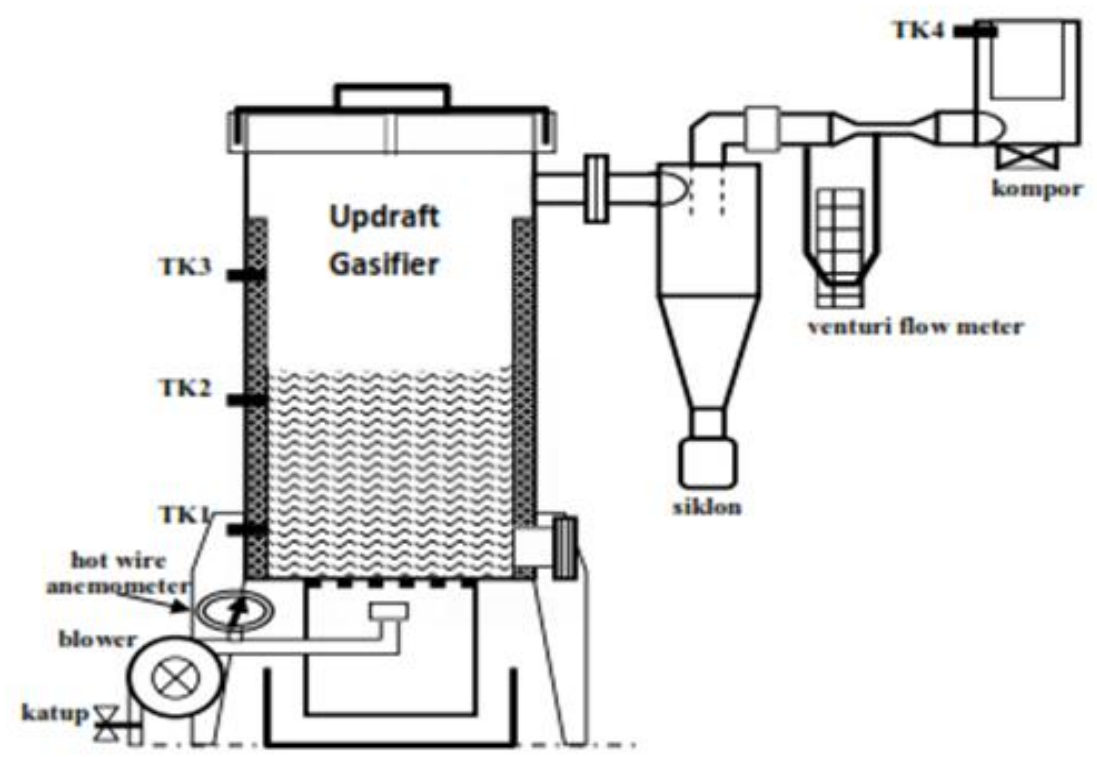

Gambar 1. Updraft Gasifier

berdasarkan bukaan katub stop kran. Pada reaktor dipasang thermocouple $\left(\mathrm{T}_{1}, \mathrm{~T}_{2}, \mathrm{~T}_{3}\right)$ untuk mengukur suhu pada saat terjadi tahapan gasifikasi. Sedangkan pengukuran suhu penyalaan syngas dilakukan pada kompor dengan termokopel $4\left(\mathrm{~T}_{4}\right)$. Adapun perlakuan yang dicobakan adalah beberapa level laju aliran udara (air flow rate) dinyatakan dalam liter per minute (l/menit) yaitu $\mathrm{V}_{1}$ (366.07 l/menit), $\mathrm{V}_{2}$ (462.09 l/menit), dan $V_{3}(545.11 \mathrm{l} /$ menit). Instrument untuk pengukuran suhu yaitu thermocouple type J, termodigital, dan pengukuran laju aliran udara adalah hot wire anemometer. Sedangkan biomassanya yaitu tempurung kemiri (kadar air 10\%), setiap perlakuan $4.0 \mathrm{~kg}_{\text {bahan }}$. Parameter yang diukur dalam penelitian ini adalah suhu proses gasifikasi $\left(\mathrm{T}_{1}, \mathrm{~T}_{2}, \mathrm{~T}_{3}\right.$, suhu penyalaan syngas $\left(\mathrm{T}_{4}\right)$, waktu penyalaan syngas (total waktu syngas dapat menyala), waktu efektif proses gasifikasi (waktu penyalaan syngas per kilogram bahan), arang dan abu tersisa $(\mathrm{kg})$.

\section{HASIL DAN PEMBAHASAN}

Hasil gasifikasi tempurung kemiri menggunakan updraft gasifier dengan berbagai laju aliran udara (air flow rate) menunjukkan bahwa efisiensi proses gasifikasi terbaik terjadi pada laju aliran udara $V_{2}$ (462.09l/menit). Beberapa parameter yang diukur pada proses gasifikasi tempurung kemiri yaitu :

\subsection{Suhu Proses Gasifikasi}

Suhu proses gasifikasi diukur dengan thermocouple yang ditempatkan pada zona reaktor gasifier. Rata-rata pada reaktor dapat dilihat pada 3 thermocouple yang terpasang pada reactor gasifier. Pada $\mathrm{T}_{1}, \mathrm{~T}_{2}, \mathrm{~T}_{3}$ untuk semua perlakuan terlihat bahwa bahwa rata-rata berkisar antara $128-619.34^{\circ} \mathrm{C}$. Hal ini menunjukkan pada kisaran suhu tersebut bahwa telah terjadi proses pengeringan, pirolisis, oksidasi dan reduksi.

Gambar 2 menunjukkan bahwa jika laju aliran udara yang disuplai ke dalam reaktor makin besar, maka oksigen yang tersedia untuk oksidasi parsial bahan bakar akan makin besar sehingga bahan bakar dapat teroksidasi dengan baik. Oksidasi parsial merupakan proses eksoterm yang memanfaatkan suplai oksigen terbatas dalam reaktor dan melepas sejumlah panas. Panas yang dilepas dari proses oksidasi digunakan untuk proses pirolisis, pengeringan dan reduksi (Purwantana, dkk. 2013).

\subsection{Suhu Penyalaan Syngas}

Suhu penyalaan syngas diukur pada kompor (burner) dengan rata-rata suhu pada semua perlakuan berada pada kisaran $592-748^{\circ} \mathrm{C}$. Hal ini menunjukkan bahwa proses dekomposisi termal dari bahan tempurung kemiri melalui pemberian sejumlah panas dengan suplai oksigen terbatas dapat menghasilkan synthesis gas 


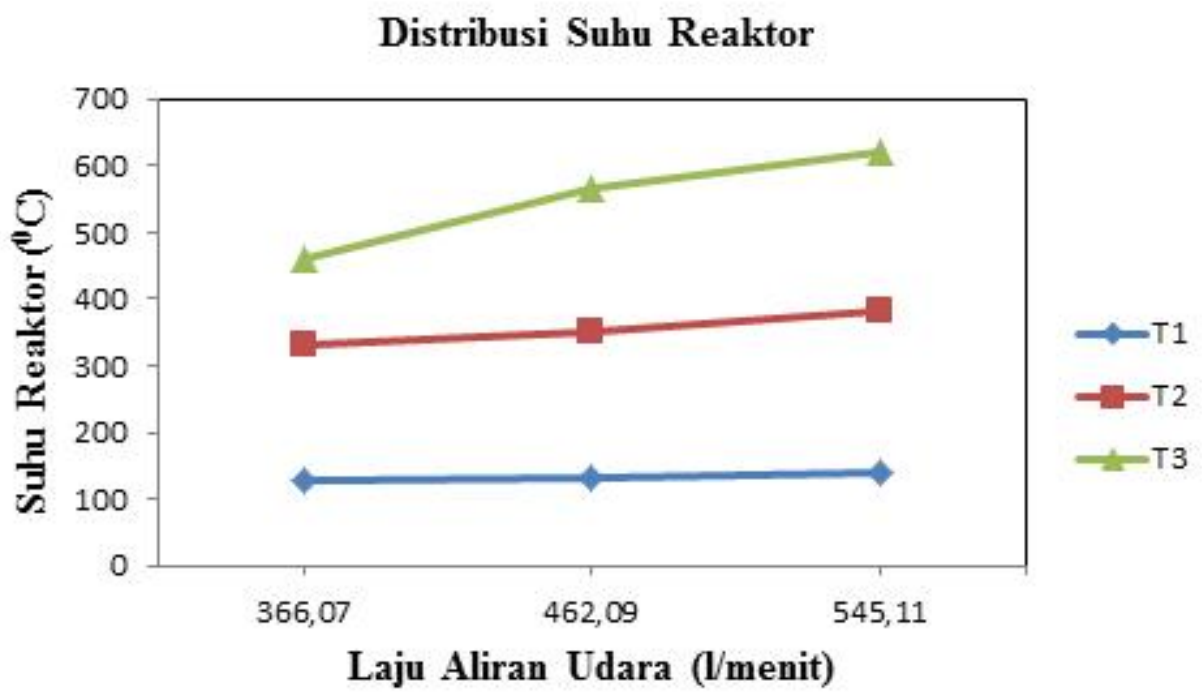

Gambar 2. Rata-Rata Suhu Reaktor

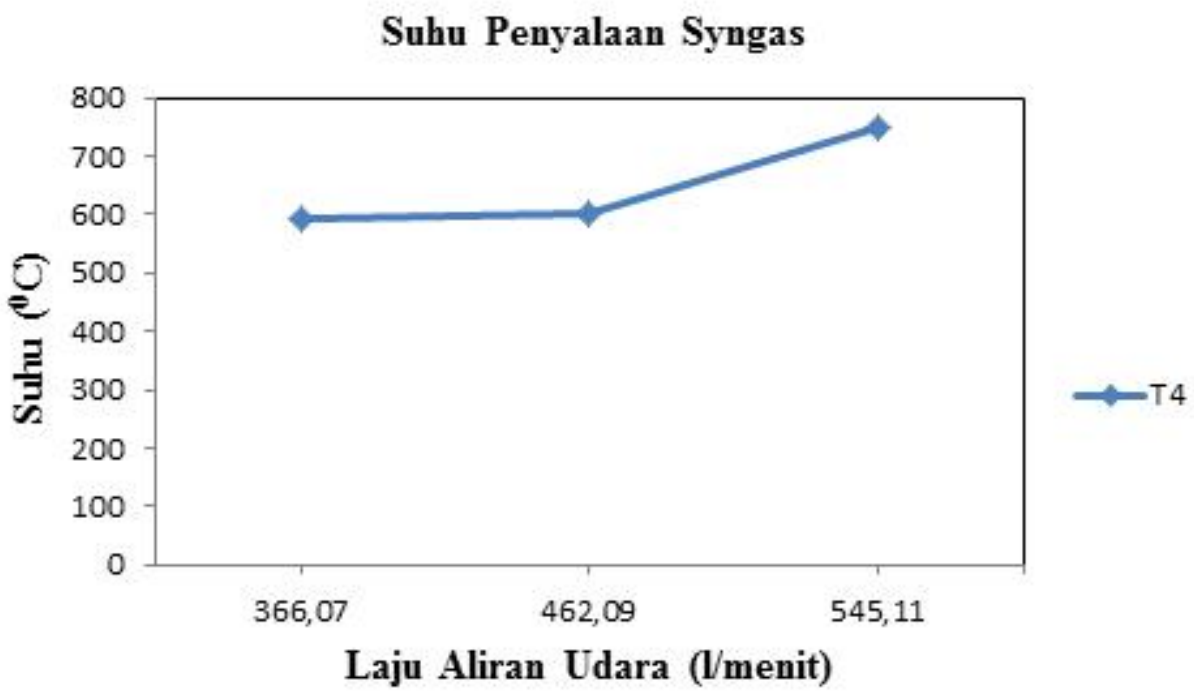

Gambar 3. Suhu Penyalaan Syngas

(syngas) yang terdiri dari $\mathrm{CO}, \mathrm{H}_{2}$, dan $\mathrm{CH}_{4}$ (Basu, 2010). Hasil dari proses dekomposisi tersebut dapat dinyalakan, sehingga nyala api pada burner mencapai suhu tertentu. Tingginya suhu penyalaan syngas ini menunjukkan bahwa syngas yang dihasilkan sangat berpotensi untuk digunakan sebagai energi alternatif.

\subsection{Waktu Penyalaan Syngas}

Waktu penyalaan syngas ditentukan berdasarkan lama syngas tersebut dapat menyala. Hasil menunjukkan bahwa Waktu penyalaan syngas terbaik pada perlakukan laju aliran udara (462.09 l/menit) dengan rata-rata lama penyalaan adalah 48 menit $/ 4 \mathrm{~kg}_{\text {bahan }}$. Dari total waktu penyalaan syngas tersebut dihasilkan waktu efektif proses syngas yaitu 12 menit $/ \mathrm{kg}_{\text {bahan }}$. Cepat atau lambatnya proses penyalaan syngas sangat tergantung pada laju aliran udara yang disuplai pada reaktor gasifier. Semakin besar udara yang disuplai ke reaktor akan mempercepat proses oksidasi, sehingga proses dekomposisi biomassa akan makin cepat (Vidian, 2004). Pada perlakuan $\mathrm{V}_{1}$ (366.07 l/ menit) waktu penyalaan rata-rata (50 menit) paling lama, namun nyala syngas pada burner kadang terlihat padam, sehingga disimpulkan bahwa proses dekomposisi tempurung kemiri tidak berjalan baik. Proses dekomposisi bahan bakar sangat tergantung dari panas yang dihasilkan untuk proses pirolisis. Jika panas yang dibutuhkan untuk untuk proses pirolisis tidak 


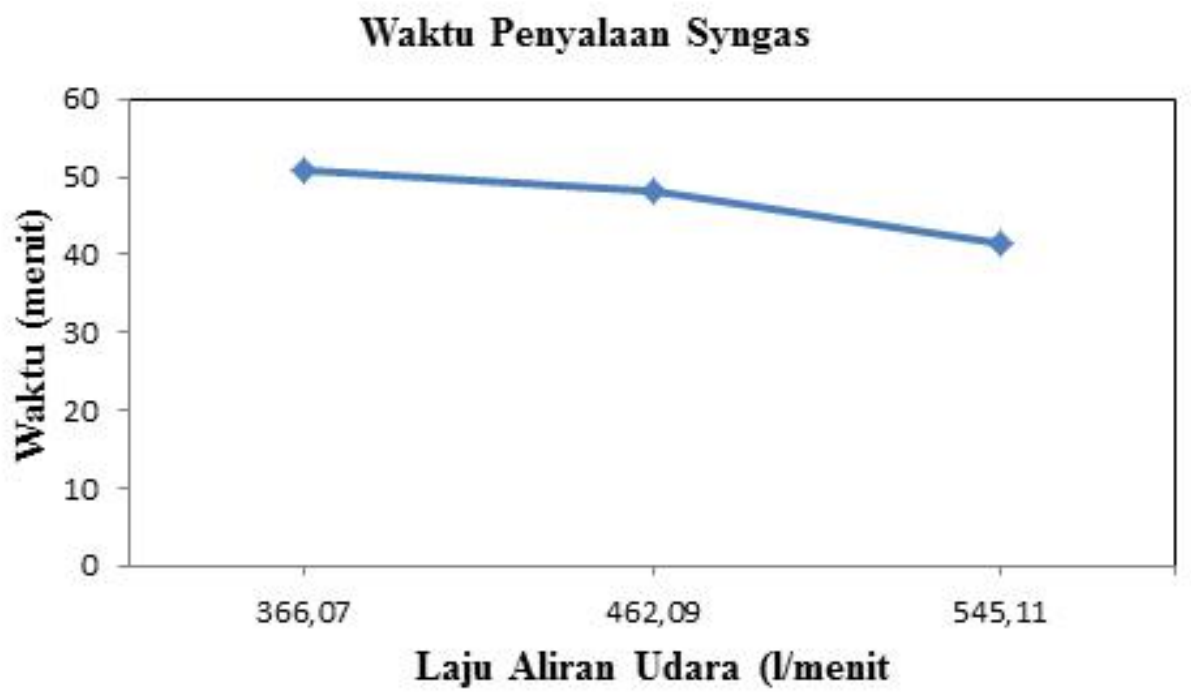

Gambar 4. Rata-Rata Waktu Penyalaan Syngas

cukup maka dekomposisi bahan bakar menjadi gas dan produk lain tidak dapat berlangsung dengan baik. Sebaliknya jika udara berlebihan, akan terjadi pembakaran sempurna pada perlakuan $\mathrm{V}_{3}(545.11 \mathrm{l} /$ menit) sehingga syngas yang dihasilkan menjadi lebih kecil (41 menit). Pada perlakuan $\mathrm{V}_{2}$ (462.09l/menit) udara yang tersedia untuk proses oksidasi parsial tersedia cukup. Hal ini ditunjukkan dengan syngas yang dinyalakan tidak padam pada proses gasifikasi. Pada perlakuan (366.07 l/menit) lebih lama, tetapi nyala syngas pada burner kadang terlihat padam. Sehingga disimpulkan bahwa waktu penyalaan terbaik terjadi pada perlakuan (462.09 l/menit) dengan waktu penyalaan mencapai 48 menit $/ 4 \mathrm{~kg}_{\text {bahan }}$. Hal ini berarti bahwa untuk setiap kg bahan bakar, lama penyalaan syngas mencapai 12 menit.

\subsection{Arang dan Abu Tersisa}

Arang dan abu sisa proses pembakaran ditimbang dan dihitung sebagai massa sisa hasil gasifikasi. Hasil analisis terhadap rata-rata massa arang dan abu sisa hasil gasifikasi menunjukkan makin besar suplai udara ke reaktor gasifier maka massa arang dan abu makin kecil. Ratarata arang dan abu tersisa pada perlakuaan $V_{1}=$ $2372 \mathrm{gr} \mathrm{V}_{2}=927 \mathrm{gr}$ dan $\mathrm{V}_{3}=968 \mathrm{gr}$. Massa arang dan abu yang terkecil terjadi pada perlakuan $V_{2}$ (462.09 lpm) karena terjadi oksidasi parsial, sehingga proses pirolisi terjadi tuntas sehingga menghasilkan arang karbon dan abu yang lebih kecil.

\section{KESIMPULAN}

Hasil penelitian gasifikasi tempurung kemiri dengan laju aliran udara (air flow rate) dapat disimpulkan bahwa hasil gasifikasi terbaik terjadi pada laju aliran udara $462.09 \mathrm{l} /$ menit dengan suhu reaktor berkisar $352,75^{\circ} \mathrm{C}$, suhu penyalaan syngas $600^{\circ} \mathrm{C}$, waktu efektif proses penyalaan syngas 12 menit $/ \mathrm{kg}_{\text {bahan }}$.

\section{DAFTAR PUSTAKA}

Abineno, J.C. 2012. Gasifikasi Tandan Kosong Kelapa Sawit Menggunakan Updraft Gasifier Dengan Variasi Laju Aliran Udara. Partner, Buletin Pertanian Terapan Volume 2 Hal. 09. Politeknik Pertanian Negeri Kupang.

Basu, P. 2010. Biomass Gasification and Pirolisys: Practical Design. UK. Elsevier.

Chopra, S and A. Jain. 2007. "A review of Fixed Bed Gasificatiion System for Biomass" Agricultural Engineering International : The CIGR Ejournal, No. 5. Vol. IX.

Pathak, B.S, S.R. Patel, A.G. Bhave, P.R. Bhoi, A.M. Sharma and N.P. Shah. 2008. Performance Evaluation of and Agriultural Residue-based Modular Throath-type Down-draft Gasifier for 
Gasifikasi Limbah Tempurung Kemiri... (Abineno J C dan Koylal J A)

Thermal Application. Journal Biomass Vidian, F. 2004. Gasifikasi Tempurung Kelapa and Energy 32 (2008) 72-78 - Elsevier.

Purwantana, B; Prastowo, B; dan Abineno, J.C. 2013. Gasifikasi Tandan Kosong Kelapa Sawit menggunakan Updraft Gasifier. Jurnal Teknotan Volume 07. 2013. Menggunakan Updraft Gasifier pada Beberapa Variasi Laju Alir Udara Pembakaran. Jurnal Teknik Mesin. Vol. 10, No. 2, Oktober 2008: 88-93. http:// www.getcited.org/pub/103470063. 